\title{
Economic Costs of Diabetes in the U.S. in 2012
}

\section{American Diabetes Association}

OBJECTIVE-This study updates previous estimates of the economic burden of diagnosed diabetes and quantifies the increased health resource use and lost productivity associated with diabetes in 2012.

RESEARCH DESICN AND METHODS - The study uses a prevalence-based approach that combines the demographics of the U.S. population in 2012 with diabetes prevalence, epidemiological data, health care cost, and economic data into a Cost of Diabetes Model. Health resource use and associated medical costs are analyzed by age, sex, race/ethnicity, insurance coverage, medical condition, and health service category. Data sources include national surveys, Medicare standard analytical files, and one of the largest claims databases for the commercially insured population in the U.S.

RESULTS - The total estimated cost of diagnosed diabetes in 2012 is $\$ 245$ billion, including $\$ 176$ billion in direct medical costs and $\$ 69$ billion in reduced productivity. The largest components of medical expenditures are hospital inpatient care (43\% of the total medical cost), prescription medications to treat the complications of diabetes (18\%), antidiabetic agents and diabetes supplies (12\%), physician office visits (9\%), and nursing/residential facility stays (8\%). People with diagnosed diabetes incur average medical expenditures of about $\$ 13,700$ per year, of which about $\$ 7,900$ is attributed to diabetes. People with diagnosed diabetes, on average, have medical expenditures approximately 2.3 times higher than what expenditures would be in the absence of diabetes. For the cost categories analyzed, care for people with diagnosed diabetes accounts for more than 1 in 5 health care dollars in the U.S., and more than half of that expenditure is directly attributable to diabetes. Indirect costs include increased absenteeism ( $\$ 5$ billion) and reduced productivity while at work ( $\$ 20.8$ billion) for the employed population, reduced productivity for those not in the labor force ( $\$ 2.7$ billion), inability to work as a result of diseaserelated disability ( $\$ 21.6$ billion), and lost productive capacity due to early mortality $(\$ 18.5$ billion).

CONCLUSIONS - The estimated total economic cost of diagnosed diabetes in 2012 is \$245 billion, a $41 \%$ increase from our previous estimate of $\$ 174$ billion (in 2007 dollars). This estimate highlights the substantial burden that diabetes imposes on society. Additional components of societal burden omitted from our study include intangibles from pain and suffering, resources from care provided by nonpaid caregivers, and the burden associated with undiagnosed diabetes.

Diabetes Care 36:1033-1046, 2013
D iabetes imposes a substantial burden on the economy of the U.S. in the form of increased medical costs and indirect costs from work-related absenteeism, reduced productivity at work

and at home, reduced labor force participation from chronic disability, and premature mortality $(1,2)$. In addition to the economic burden that has been quantified, diabetes imposes high intangible

\footnotetext{
$\bullet \bullet \bullet \bullet \bullet \bullet \bullet \bullet \bullet \bullet \bullet \bullet \bullet \bullet \bullet \bullet \bullet \bullet \bullet \bullet \bullet \bullet \bullet \bullet \bullet \bullet \bullet \bullet \bullet \bullet \bullet \bullet \bullet \bullet \bullet \bullet \bullet \bullet \bullet \bullet \bullet \bullet \bullet \bullet \bullet \bullet \bullet \bullet \bullet$

This report was prepared under the direction of the American Diabetes Association by Wenya Yang (The Lewin Group, Inc., Falls Church, Virginia); Timothy M. Dall (IHS Global Inc., Washington, DC); Pragna Halder (The Lewin Group, Inc.); Paul Gallo (IHS Global Inc.); Stacey L. Kowal (IHS Global Inc.); and Paul F. Hogan (The Lewin Group, Inc.).

Address correspondence to Matt Petersen, American Diabetes Association, 1701 N. Beauregard Street, Alexandria, VA 22311. E-mail: mpetersen@diabetes.org.

DOI: $10.2337 / \mathrm{dc} 12-2625$

This article contains Supplementary Data online at http://care.diabetesjournals.org/lookup/suppl/doi:10 .2337/dc12-2625/-/DCl.

(C) 2013 by the American Diabetes Association. Readers may use this article as long as the work is properly cited, the use is educational and not for profit, and the work is not altered. See http://creativecommons.org/ licenses/by-nc-nd/3.0/ for details.
}

See accompanying commentary, p. 775. costs on society in terms of reduced quality of life and pain and suffering of people with diabetes, their families, and friends.

Improved understanding of the economic cost of diabetes and its major determinants helps to inform policymakers and to motivate decisions to reduce diabetes prevalence and burden. The previous cost of diabetes study by the American Diabetes Association (ADA) estimated that there were nearly 17.5 million people living in the U.S. with diagnosed type 1 or type 2 diabetes in 2007, at an estimated cost of $\$ 174$ billion in higher medical costs and lost productivity (2).

The percentage of the population with diagnosed diabetes continues to rise, with one study projecting that as many as one in three U.S. adults could have diabetes by 2050 if current trends continue (3). In this updated cost of diabetes study, we estimate the total national economic burden of diagnosed diabetes in 2012 reflecting continued growth in prevalence of diabetes and its complications; changing health care practices, technology, and cost of treatment; and changing economic conditions.

\section{RESEARCH DESICN AND}

METHODS - This study follows the methodology used in the 2002 and 2007 costs of diabetes studies by the ADA, with modifications to refine the analyses where appropriate $(1,2)$. A prevalencebased approach is used to estimate the medical costs by demographic group, health service category, and medical condition. One difference from earlier studies is that for some analyses we now include race/ethnicity as a demographic dimension. We analyze the prevalence of diagnosed diabetes, utilization and costs attributable to diabetes by age-group (under $18,18-34,35-44,45-54,55-59$, $60-64,65-69$, and over 70 years of age), sex, race/ethnicity (non-Hispanic white, non-Hispanic black, non-Hispanic other, and Hispanic), and insurance status (private; government including Medicare, Medicaid, Children's Health Insurance Program, and other government-sponsored coverage; and uninsured). State-specific estimates of prevalence and costs are provided in Supplementary Table 11. 
Major data sources analyzed include National Health Interview Survey (NHIS), American Community Survey (ACS), Behavioral Risk Factor Surveillance System (BRFSS), Medical Expenditure Panel Survey (MEPS), OptumInsight's de-identified Normative Health Information database (dNHI), the Medicare 5\% sample Standard Analytical Files (SAFs), Nationwide Inpatient Sample (NIS), National Ambulatory Medical Care Survey (NAMCS), National Hospital Ambulatory Medical Care Survey (NHAMCS), National Nursing Home Survey (NNHS), National Home and Hospice Care Survey (NHHCS), and Current Population Survey (CPS). We use the most recent year's data available for each of these data sources, though for certain analyses we combine 3 years of data to achieve sufficient sample size. To estimate medical costs for less common health service categories such as hospital inpatient care, emergency care, home health, and podiatry, we combine 5 years of MEPS data to reduce variance in utilization and cost. The demographics of the U.S. population in 2012 with diabetes prevalence, epidemiological data, health care cost, and economic data are then combined into a Cost of Diabetes Model. Supplementary Table 1 describes how these data sources are used, along with their respective strengths and limitations, pertinent to this study. All cost and utilization estimates are extrapolated to the projected U.S. population in 2012 (4), with cost estimates calculated in 2012 dollars using the appropriate components of the medical consumer price index or total consumer price index (5).

\section{Estimating the size of the population with diabetes}

To estimate the number of people with diagnosed diabetes in 2012 we combined U.S. Census Bureau population numbers with estimated prevalence of diabetes by age-group, sex, race/ethnicity, insurance coverage, and whether residing in a nursing home.

Combining the 2009, 2010, and 2011 NHIS data produced a sample sufficient to estimate diabetes prevalence by demographic and insurance coverage $(n=123,185)$. Prevalence is based on respondents answering "yes" to the question, "Have you EVER been told by a doctor or health professional that you have diabetes or sugar diabetes?" We exclude gestational diabetes mellitus from the prevalence estimates. Previous research finds that self-report of a physician's diagnosis of diabetes is accurate in estimating prevalence of diagnosed diabetes (6).

For the 2007 cost study, the estimated prevalence of diagnosed diabetes among the institutionalized population (24\%) came from an analysis of the 2004 NNHS. There has been no update of the NNHS since 2004. Nearly one in three (32.8\%) nursing home residents has diagnosed diabetes based on a nationally representative study that analyzed medical charts, minimum dataset records, and prescription claims files to identify people with diabetes (7). On the basis of this updated information on diabetes prevalence among nursing home residents, we estimate age-group-, sex-, and race/ethnicityspecific prevalence using the same distribution of the population demographic variables as shown in the 2004 NNHS survey data among the 1.6 million nursing home residents in 2012. Few data exist regarding the prevalence of diabetes among the noncivilian population or the institutionalized populations other than those in nursing homes (e.g., in prisons). We assume that the noncivilian population and the institutionalized populations other than those in nursing homes have diabetes prevalence similar to the noninstitutionalized population, controlling for demographics, based on the limited evidence available $(8,9)$.

Combining the NHIS and NNHS data, we estimate the prevalence of diagnosed diabetes among population subgroups (by age-group, sex, race/ethnicity, and insurance coverage). Supplementary Table 3 shows that prevalence of diabetes increases with age, is somewhat higher for males than for females, and is highest among non-Hispanic blacks. Reflecting the high prevalence among the elderly population, $13.4 \%$ of the population with government-sponsored medical insurance (e.g., Medicare, Medicaid) has diagnosed diabetes as compared with $4.6 \%$ among the privately insured and 3.7\% among the uninsured populations.

State-specific estimates of diabetes prevalence (Supplementary Table 11) come from combing the 2010 ACS, the 2009 and 2010 BRFSS, and the 2004 NNHS. We applied a statistical matching procedure that randomly matches each person in the 2010 ACS with a similar person either in the BRFSS (if not living in a nursing home) or in the NNHS (if living in a nursing home). Each noninstitutionalized person in the ACS is matched with a person in the BRFSS in the same state, sex, age-group (15 age-groups), race/ethnicity, household income level (eight levels), and insured/uninsured status. Each person in the ACS in a nursing/ residential facility is matched with a person in the NNHS in the same sex, age-group, and race/ethnicity. Our state prevalence estimates are slightly different from those reported by the U.S. Centers for Disease Control and Prevention (CDC) for 2010, which are based solely on the BRFSS (10).

\section{Estimating the direct medical cost attributed to diabetes}

We estimate health resource use among the population with diabetes in excess of resource use that would be expected in the absence of diabetes. Diabetes increases the risk of developing neurological, peripheral vascular, cardiovascular, renal, endocrine/metabolic, ophthalmic, and other complications (see Supplementary Table 2 for a more comprehensive list of comorbidities) (2). Diabetes also increases the cost of treating general conditions that are not directly related to diabetes $(2,11-$ 13). Therefore, a portion of health care expenditures for these medical conditions is attributed to diabetes.

As elaborated in the 2007 study, the approach used to quantify the increase in health resource use associated with diabetes was influenced by four data limitations: 1) absence of a single data source for all estimates, 2) small sample size in some data sources, 3) correlation of both diabetes and its comorbidities with other factors such as age and obesity, and 4) under-reporting of diabetes and its comorbidities in certain data sources. Because of these limitations we estimate diabetes-attributed costs using one of two approaches for each cost component.

For cost components estimated solely from the MEPS (ambulance services, home health, podiatry, diabetic supplies, and other equipment and supplies), we use a simple comparison of annual per capita health resource use for people with and without diabetes controlling for age, sex, and race/ethnicity. For nursing/ residential facility use (which is not captured in the MEPS) and for cost components that rely on analysis of medical encounter data (hospital inpatient, emergency care, and ambulatory visits), we use an attributed risk methodology often used in disease-burden studies that relies on population etiological fractions $(2,14)$. Etiological fractions estimate the excess use of health care services among the diabetic population relative to a similar population that does not have diabetes. 
Both approaches are equivalent under a reasonable set of assumptions, but the first approach cannot be used with some national data sources analyzed (e.g., NIS) that are visit/hospital discharge level files, which might or might not identify the patient as having diabetes even if the patient does indeed have diabetes $(2,14)$.

The attributable fraction approach combines etiological fractions $(\boldsymbol{\varepsilon})$ with total projected U.S. health service use $(U)$ in 2012 for each age-group (a), sex (s), medical condition $(c)$, and care delivery setting $(H)$-hospital inpatient, emergency departments, and ambulatory visits (physician office visits combined with hospital outpatient/clinic visits):

Attributed health resource use $_{H}$

$$
=\sum_{\text {age sex }} \sum_{\begin{array}{c}
\text { medical } \\
\text { condition }
\end{array}} \varepsilon_{H, a, s, c} \times U_{H, a, s, c}
$$

The etiological fraction is calculated using the diagnosed diabetes prevalence $(P)$ and the relative rate ratio $(R)$ :

$$
\boldsymbol{\varepsilon}_{H, a, s, c}=\frac{P_{a, s} \times\left(R_{H, a, s, c}-1\right)}{P_{a, s} \times\left(R_{H, a, s, c}-1\right)+1}
$$

The rate ratio for hospital inpatient days, emergency visits, and ambulatory visits represents how annual per capita health service use for the population with diabetes compares to the population without diabetes:

$$
\begin{aligned}
& R_{H, a, s, c} \\
& =\frac{\text { annual per capita use for people with diabetes }}{a, s, c} \\
& \text { annual per capita use for people without diabetes }{ }_{a, s, c}
\end{aligned}
$$

Diabetes and its comorbidities are correlated with other patient characteristics (e.g., demographics and body weight). To mitigate bias caused by correlation, we estimate age/sex/setting-specific etiological fractions for each medical condition. The primary data sources for calculating etiological fractions are OptumInsight's $\mathrm{dNHI}$ data (a consolidation of the Ingenix Research Data Mart and MCURE databases used in the 2007 study) and the 2010 5\% sample Medicare SAFs. The dNHI data contains a complete set of medical claims for over 23 million commercially insured beneficiaries in 2011 and allows patient records to be linked during the year and across health delivery settings. This allows us to identify people with a diabetes ICD-9 diagnosis code (250.xx) in any of their medical claims during the year. The Medicare 5\% sample SAFs contain claims data filed on behalf of Medicare beneficiaries under both Part $A$ and Part B, and like the dNHI we identify people with diabetes based on diabetes ICD-9 diagnosis codes. The large size of these two claims databases enables the generation of age/sex/setting-specific rate ratios for each medical condition, which are more stable than rates estimated using the MEPS.

Unlike the MEPS, the dNHI data and Medicare 5\% claims data do not contain race/ethnicity and select patient characteristics that could affect both patients' health status and health seeking behaviors. For the 10 medical conditionscataract, cellulitis, conduction disorders and cardiac dysrhythmias, general medical condition, heart failure, hypertension, myocardial infarction, other chronic ischemic heart disease, renal failure and its sequelae, and urinary tract infectionwhich are the largest contributors to the overall cost of diabetes, we estimated two multivariate Poisson regressions, using data from the MEPS, to determine the extent to which controlling only for age and sex might bias the rate ratios. First, we estimated a naive model that produces diabetes-related rate ratios for hospital inpatient days, emergency visits, and ambulatory visits controlling for age and sex only. Then, we estimated a full model that includes diabetes status as the main explanatory variable and various known predictors of health service utilization including age, sex, education level, income, marital status, medical insurance status, and race/ethnicity as covariates. For the full model our focus is not on the relationship between health care use and the covariates (other than diabetes), but rather these covariates are included to control for patient characteristics not available in medical claims data that could be correlated with both medical conditions and health-seeking behavior. The full model omits indicators for the presence of coexisting conditions or complications of diabetes (e.g., hypertension), since including such variables could bias low the estimated relationship between diabetes and health care use for each of the 10 medical conditions. The rate ratio coefficients for the diabetes flag variable in the naive and full models are then compared. The findings suggest statistically significant overestimates of the rate ratios for emergency visits when using the naïve model for five condition categories. For inpatient days, we found significant overestimates in the rate ratios for three condition categories. For ambulatory visits, only hypertension was found to have a significantly higher rate ratio by comparing the MEPS-based naive model and the full model.

To remedy the relative risk overestimation for these condition categories, we scaled the rate ratios estimated from dNHI and Medicare 5\% sample using the regression results from the MEPS analysis by applying a scalar (with the scalar calculated as the full model rate ratio divided by the naive model rate ratio) (2). For emergency department visits, claims-based rate ratios were scaled down for myocardial infarction (scale $=0.94$ ), other chronic ischemic heart disease (0.93), hypertension (0.71), cellulitis (0.72), and renal failure (0.95). For inpatient days, claims-based rate ratios were scaled down for hypertension (0.62), cellulitis (0.93), and renal failure (0.90). Physician office visits were scaled down for hypertension (0.89). We did not find a significant overestimate of the rate ratios for general medical conditions for any of the three health service delivery settings comparing the MEPS-based naive model and the full model. However, a comparison of the claims-based rate ratios with the rate ratios calculated from the MEPS-based naive model found that the claims-based rate ratios for general conditions were significantly higher than the MEPS-based rate ratios for emergency department visits, hospital inpatient days, and ambulatory visits, respectively. Therefore, to be conservative in our cost estimates, we downward adjusted claimsbased rate ratios for emergency department visits (0.70), hospital inpatient days (0.68), and ambulatory visits (0.66) for the general condition group by applying a scalar calculated as the MEPS-based naivve model rate ratio divided by the claims-based rate ratio.

Estimates of health resource use attributed to diabetes were combined with estimates of the average medical cost per event, in 2012 dollars, to compute total medical costs attributed to diabetes. For hospital inpatient days, office visits, emergency visits, and outpatient visits, we use average cost per visit/day specific to the medical conditions modeled. We combined the 2008-2010 MEPS files to estimate the average cost per event, except that for less common conditions or cost categories we combined the 2006-2010 MEPS files to obtain a larger sample and thereby produce more precise cost estimates. Although the MEPS contains both inpatient facility and professional 
expenditures and the NIS contains only facility charges (which are converted to costs using hospital-specific cost-to-charge ratios), the NIS has a much larger sample ( $n=\sim 8$ million discharges in 2010) and also contains 5-digit diagnosis codes. Therefore, we use the 2010 NIS to estimate inpatient facility costs and the combined 2008-2010 MEPS to estimate the cost for professional services. The average costs per event or day by medical condition are shown in Supplementary Table 4.

Utilization of prescription medication (excluding insulin and other antidiabetic agents) for each medical condition is estimated from medications prescribed during physician's office, emergency department, and outpatient visits attributed to diabetes. The average number of medications prescribed during a visit for each age-sex-race stratum was estimated from 2008-2010 NAMCS and 2007-2009 NHAMCS data. We calculated the total number of people with diabetes that use insulin and other antidiabetic agents by combining diabetes prevalence and rate of use for these antidiabetic agents obtained from the 2009-2011 NHIS. The average cost per prescription filled, insulin, and oral and other antidiabetic agents were obtained from the combined MEPS 2008-2010. We combined the utilization of these medications with the average cost per prescription to estimate the cost by age, sex, race/ethnicity, and insurance status. The average per capita cost for diabetic supplies by age-sex-race stratum was calculated from the MEPS 20082010. Over-the-counter medications were not included owing to the lack of data on whether diabetes increases the use of such medications.

Consistent with the 2007 study, total nursing/residential facility days attributed to diabetes were estimated by combining the average length of stay and the nursing/ residential facility population. Using 2004 NNHS, we calculated the number of residents with diabetes in each age-sex stratum, which was adjusted using the $32.8 \%$ diabetes prevalence estimate among nursing home residents, obtained from literature (7). Nursing/residential facility use attributed to diabetes was estimated using an attributable risk approach where the prevalence of diabetes among residents was compared with the prevalence of diabetes among the overall population in the same age-sex stratum. The analyses were conducted separately for short-stay, long-stay, and residential facility residents to estimate total days of care. Similar to the 2007 study, cost per day was obtained from a geographically representative cost of care survey for 2012 (15).

Hospice days attributed to diabetes represents a combination of length of stay and diabetes prevalence among hospice residents. The 2007 NHHCS was used to calculate the number of hospice residents with diabetes and those that have a primary diagnosis of diabetes along with the average length of stay for each age-sex-race stratum. Cost per resident per day obtained from the Hospice Association of America was combined with hospice days attributed to diabetes to estimate the total cost of hospice care attributed to diabetes.

The 2006-2010 MEPS files were combined to increase the sample size to analyze the use of home health, podiatry, ambulance services, and other equipment and supplies. These cost components are estimated by comparing annual per capita cost for people with and without diabetes, controlling for age. Due to small sample size, sex and race/ethnicity were not included as a stratum when calculating costs per capita.

\section{Estimating the indirect cost attributed to diabetes}

The indirect costs associated with diabetes include workdays missed due to health conditions (absenteeism), reduced work productivity while working due to health conditions (presenteeism), reduced workforce participation due to disability, and productivity lost due to premature mortality (16-18). Productivity loss occurs among those in the labor force as well as among the nonemployed population. To estimate the value of lost productivity, we calculate the number of missed workdays resulting from absenteeism, reduced work productivity due to presenteeism, workforce participation reductions associated with chronic disability, and work years lost resulting from premature mortality associated with diabetes. This approach mirrors the one used in the 2007 study, with the exception of adding race/ethnicity as a dimension. More recent data sources were used with per capita productivity loss calculated by combining the estimates derived from the 2009-2011 NHIS and the average annual earnings from the 2011 CPS. Earnings were inflated to 2012 dollars using the overall consumer price index, and per capita estimates were applied to the number of people with diabetes by age-group, sex, and race/ethnicity.

- Absenteeism is defined as the number of workdays missed due to poor health, and prior research finds that people with diabetes have higher rates of absenteeism than the population without diabetes (16-18). Estimates of excess absenteeism associated with diabetes range from 1.8 to $7 \%$ of total workdays $(17,19-22)$. Ordinary least squares regression with the 2009-2011 NHIS shows that self-reported annual missed workdays are statistically higher for people with diabetes. Control variables include age-group, sex, race/ethnicity, diagnosed hypertension status (yes/no), and body weight status (normal, overweight, obese, unknown). Diabetes is entered as a dichotomous variable (diagnosed diabetes $=1$; otherwise 0 ), as well as an interaction term with agegroup. Controlling for hypertension and body weight produces more conservative estimates of the diabetes impact on absenteeism as comorbidities of diabetes are correlated with body weight status and a portion of hypertension is attributed to diabetes. Workers with diabetes average three more missed workdays than their peers without diabetes, with excess missed workdays varying by demographic group.

- Presenteeism is defined as reduced productivity while at work, and is generally measured through worker responses to surveys. These surveys rely on the self-reported inputs on the number of reduced productivity hours incurred over a given time frame. Multiple recent studies report that individuals with diabetes display higher rates of presenteeism than their peers without diabetes $(19,21,22)$. The rate of presenteeism among the population with diabetes exceeds rates for their colleagues without diabetes-with the excess rates ranging from 1.8 to $38 \%$ of annual productivity (17,19-22). These estimates comparing presenteeism for employees with diabetes versus those without diabetes, however, fail to control for other factors that may be correlated with diabetes (e.g., age and weight status). Consequently, we model productivity loss associated with diabetes-attributed presenteeism using the estimate (6.6\%) from the 2007 study that controls for the impact of factors correlated with diabetes (2). 
- Inability to work associated with diabetes is estimated using a conservative approach that focuses on unemployment related to long-term disability. The CDC estimates that roughly 65,700 lower-limb amputations are performed each year on people with diabetes (23). These amputations and other comorbidities of diabetes can make it difficult for some people with diabetes to remain in the workforce or to find employment in their chosen profession $(22,24)$. To quantify diabetes-related disability, we identify people in the 2009-2011 NHIS between ages 18 and 65 years who receive Supplemental Security Income (SSI) payments for disability. Using logistic regression, we estimate the relationship between diabetes and the receipt of SSI payments controlling for age-group, sex, race/ethnicity, hypertension, and weight. The results of this analysis suggest that people with diabetes have a 2.4 percentage point higher rate of being out of the workforce and receiving disability payments compared with their peers without diabetes. The diabetes effect increases with age and varies by demographic-ranging from 0.7 percentage points for non-Hispanic white males aged 65-69 years to 7.4 percentage points for non-Hispanic black females aged 55-59 years. Modeling disability-related unemployment is a conservative approach to modeling the employment effect of diabetes; regression analysis of the NHIS suggests that people with diabetes have actual labor force participation rates averaging approximately 10 percentage points lower than their peers without diabetes. The average daily earnings for those in the workforce are used as a proxy for the economic impact of reduced employment due to chronic disability. SSI payments are considered transfer payments and therefore are not included in the social cost of not working due to disability.

- Reduced productivity for those not in the workforce is included in our estimate of the national burden. This population includes all adults under 65 years of age who are not employed (including those voluntarily or involuntarily not in the workforce). The contribution of people not in the workforce to national productivity includes time spent providing child care, household activities, and other activities such as volunteering in the
Table 1-Health resource use in the U.S. by diabetes status and cost component, 2012 (in millions of units)

\begin{tabular}{|c|c|c|c|c|c|c|}
\hline \multirow[b]{3}{*}{ Health resource } & \multicolumn{4}{|c|}{ Population with diabetes } & \multirow{3}{*}{$\begin{array}{l}\text { Incurred by } \\
\text { population } \\
\text { without } \\
\text { diabetes }\end{array}$} & \multirow[b]{3}{*}{$\begin{array}{c}\text { U.S. } \\
\text { total }^{*}\end{array}$} \\
\hline & \multicolumn{2}{|c|}{$\begin{array}{l}\text { Attributed } \\
\text { to diabetes }\end{array}$} & \multicolumn{2}{|c|}{$\begin{array}{l}\text { Incurred by } \\
\text { people with } \\
\text { diabetes }\end{array}$} & & \\
\hline & Units & $\begin{array}{l}\% \text { of U.S. } \\
\text { total }\end{array}$ & Units & $\begin{array}{l}\% \text { of U.S. } \\
\text { total }\end{array}$ & & \\
\hline \multicolumn{7}{|l|}{ Institutional care } \\
\hline Hospital inpatient days & 26.4 & $15.7 \%$ & 43.1 & $25.7 \%$ & 124.9 & 168.0 \\
\hline $\begin{array}{l}\text { Nursing/residential facility } \\
\text { days }\end{array}$ & 101.3 & $16.4 \%$ & 198.4 & $32.2 \%$ & 418.0 & 616.4 \\
\hline Hospice days & 0.2 & $0.3 \%$ & 9.3 & $12.8 \%$ & 63.1 & - \\
\hline Outpatient care & & & & & & $1,026.7$ \\
\hline Physician office visits & 85.7 & $8.3 \%$ & 174.0 & $16.9 \%$ & 852.8 & 128.7 \\
\hline Emergency department visits & 7.3 & $5.7 \%$ & 15.3 & $11.9 \%$ & 113.5 & 100.7 \\
\hline Hospital outpatient visits & 7.8 & $7.8 \%$ & 15.0 & $14.9 \%$ & 85.6 & 279.7 \\
\hline Home health visits & 25.7 & $9.2 \%$ & 64.9 & $23.2 \%$ & 214.7 & 72.4 \\
\hline Medication prescriptions & 361.4 & $11.8 \%$ & 673.1 & $22.1 \%$ & $2,377.9$ & $3,051.1$ \\
\hline
\end{tabular}

Data sources: NIS (2010), NNHS (2004), NAMCS (2008-2010), NHAMCS (2007-2009), MEPS (20062010), and NHHCS (2007). *Numbers do not necessarily sum to totals because of rounding. productivity for those not in the workforce were based on estimates of "bed days" (which is defined as a day spent in bed because of poor health). The NHIS no longer collects data on bed days. Therefore, we use per capita absenteeism estimates for the working population as a proxy for reduced productivity days among the nonemployed population in a similar demographic. Whereas each workday lost due to absenteeism is based on estimated average daily earnings, there is no readily available measure of the value of a day lost for those not community. Prior estimates of reduced in the workforce. Studies often use minimum wage as a proxy for the value of time lost, but this will underestimate the value of time. Using average earnings for their employed counterparts will overestimate the value of time. Similar to the 2007 study, we use $75 \%$ of the average earnings for people in the workforce as a productivity proxy for those under 65 years of age not in the labor force (which is close to the midpoint between minimum wage and the average hourly wage earned by a demographic similar to the unemployed under 65 years of age).
Table 2-Health resource use attributed to diabetes in the U.S. by age-group and type of service, 2012 (in thousands of units)

\begin{tabular}{lcccc} 
& \multicolumn{3}{c}{ Age (years) } & \\
\cline { 2 - 3 } Health resource & $\begin{array}{c}<5 \\
(n=3.3 \mathrm{M})\end{array}$ & $\begin{array}{c}45-64 \\
(n=10.2 \mathrm{M})\end{array}$ & $\begin{array}{c}\geq 65 \\
(n=8.8 \mathrm{M})\end{array}$ & $\begin{array}{c}\text { Total* } \\
(\mathrm{N}=22.3 \mathrm{M})\end{array}$ \\
\hline Institutional care & & & & \\
$\quad$ Hospital inpatient days & $1,879(<1 \%)$ & $7,969(37 \%)$ & $16,535(63 \%)$ & 26,383 \\
\hline Nursing/residential facility days & $1,456(<1 \%)$ & $18,587(20 \%)$ & $81,288(80 \%)$ & 101,331 \\
\hline Hospice days & $0(0 \%)$ & $17(9 \%)$ & $168(91 \%)$ & 186 \\
Outpatient care & & & & \\
Physician office visits & $8,077(9 \%)$ & $28,437(33 \%)$ & $49,212(57 \%)$ & 85,726 \\
\hline Emergency department visits & $1,608(22 \%)$ & $2,589(36 \%)$ & $3,084(42 \%)$ & 7,280 \\
\hline Hospital outpatient visits & $1,233(16 \%)$ & $3,241(41 \%)$ & $3,342(43 \%)$ & 7,817 \\
\hline Home health visits & $3,249(13 \%)$ & $10,409(40 \%)$ & $12,076(47 \%)$ & 25,734 \\
\hline Medication prescriptions & $27,839(8 \%)$ & $118,493(33 \%)$ & $215,105(60 \%)$ & 361,437 \\
\hline
\end{tabular}

Data sources: NIS (2010), NNHS (2004), NAMCS (2008-2010), NHAMCS (2007-2009), MEPS (20062010), and NHHCS (2007). *Numbers do not necessarily sum to totals because of rounding. 
- Premature mortality associated with diabetes reduces future productivity (and not just the current year productivity). Ideally, to model the value of lost productivity in 2012 associated with premature mortality one would calculate the number and characteristics of all people who would have been alive in 2012 but who died prior to 2012 because of diabetes. Data limitations prevent using this approach. Instead, we estimate the number of premature deaths associated with diabetes in 2012 and calculate the present value of their expected future earnings.

To estimate the total number of deaths attributable to diabetes we analyzed the CDC's 2009 Mortality Multiple Cause File to obtain mortality data by age, sex, and race/ethnicity for cardiovascular disease, cerebrovascular disease, renal failure, and diabetes. A literature review supports the 2007 ADA report estimate that $\sim 16 \%$ of cardiovascular disease (excluding cerebrovascular disease) deaths can be attributed to diabetes $(1,2,25)$. To estimate the fraction of cerebrovascular disease and renal failure deaths attributed to diabetes, we used etiological fractions for emergency department use as a proxy for mortality etiological fractions (2). Our estimates suggest that $\sim 28 \%$ of deaths listing cerebrovascular disease as the primary cause and $~ 55 \%$ of deaths listing renal failure as the primary cause can be attributed to diabetes. The elderly represent the largest population group where deaths attributable to diabetes occur, with $\sim 71 \%$ of deaths occurring among people aged $\geq 70$ years and $8 \%$ of deaths occurring among people aged 65-69 years. To generate 2012 estimates, we grow the 2009 CDC mortality data using the annual diabetic population growth rate from 2009 to 2012 for each age, sex, and race/ethnicity group.

Productivity loss associated with early mortality is calculated by taking the net present value of future productivity (PVFP) for men and women by age and race/ethnicity using the same discount rate $(3 \%)$, assumptions, and equation outlined in the 2007 ADA report (2). We combined the average annual earnings from the CPS, expected mortality rates from the CDC, and employment rates from the CPS by age, sex, and race/ethnicity to calculate the net present value of future earnings of a person who dies prematurely. Employment rates for 2007 (rather than
2012) are used to calculate PVFP as rates for 2007 are closer to the historical average (whereas rates for 2008-2012 are lower than average due to the recession). The results incorporate U.S. Bureau of Labor Statistics findings that many older workers are delaying retirement because of the economic downturn (with $\sim 15 \%$ employed at age 65 years and diminishing to $\sim 5 \%$ employed at age 70 years), with this pattern expected to exist even after the economy recovers (2).

RESULTS - In 2012, an estimated 22.3 million people in the U.S. were diagnosed with diabetes, representing about $7 \%$ of the population. This estimate is higher than but consistent with those published by the CDC for $2010(23,26)$. The estimated national cost of diabetes in 2012 is $\$ 245$ billion, of which $\$ 176$ billion ( $72 \%$ ) represents direct health care expenditures attributed to diabetes and $\$ 69$ billion (28\%) represents lost productivity from work-related absenteeism, reduced productivity at work and at home, unemployment from chronic disability, and premature mortality.

\section{Health resource use attributed to diabetes}

Table 1 shows estimates of health resource utilization attributed to diabetes and incurred by people with diabetes as a percentage of total national utilization. For example, of the projected 168 million hospital inpatient days in the U.S. in 2012, an estimated 43.1 million days (25.7\%) are incurred by people with diabetes of which 26.4 million days are attributed to diabetes. About one-third of all nursing/residential facility days are incurred by people with diabetes, and over half of those are attributed to diabetes. About half of all physician office visits, emergency department visits, hospital outpatient visits, and medication prescriptions (excluding insulin and other antidiabetic agents) incurred by people with diabetes are attributed to their diabetes.

Table 2 shows that the population aged 65 years and older uses a substantially larger portion of services, especially hospital inpatient days, nursing/residential facility days, and hospice, compared with those under age 65 years. The significant increase in nursing/residential days attributed to diabetes from the 2007 study reflects both the increasing cost and the increased prevalence of diabetes

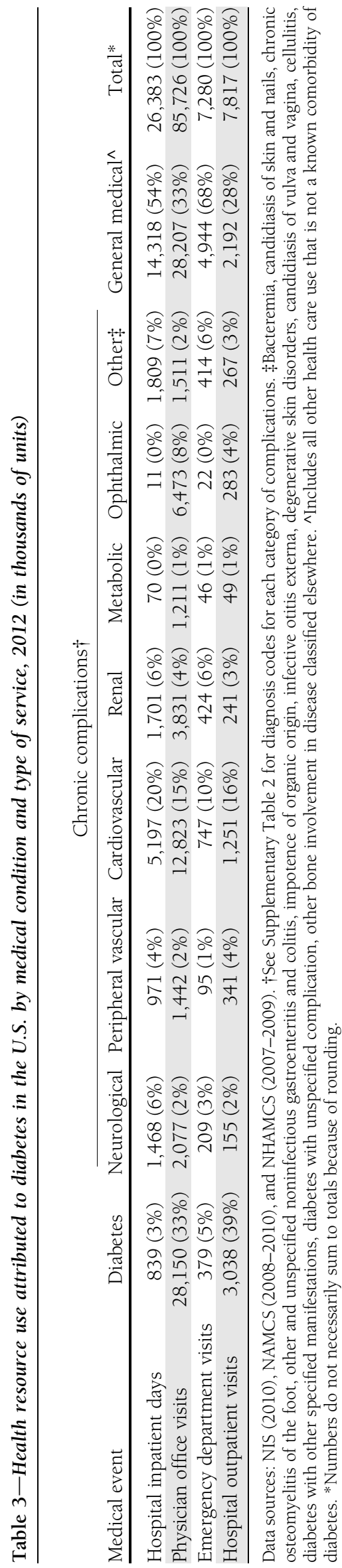


(32.8\%) in general, and among the elderly in particular. Total utilization of prescription medications attributed to diabetes has more than doubled from the estimate in the 2007 study, reflecting a dramatic increase in the use of medications treating general conditions and diabetes comorbidities among people with diabetes. Supplementary Table 5 shows the per capita health resource use by demographic.

Analysis of health resource use attributed to diabetes by medical condition (Table 3), including diabetes, chronic complications of diabetes, and general medical conditions, shows that a large portion of health resource use attributed to diabetes-particularly hospital inpatient and emergency department visits-is for general medical conditions that are not chronic complications of diabetes. As discussed in the 2007 cost of diabetes study, diabetes contributes to longer hospital length of stay regardless of the reason for admission (and controlling for other factors that affect hospital length of stay) (2). In addition to general medical conditions, a substantial amount of attributed health resource use is for chronic complications of diabetes, particularly cardiovascular diseases and renal complications. Finally, more than onethird of physician office visits and nearly $40 \%$ of hospital outpatient visits have diabetes listed as the primary reason for the visit. Supplementary Table 8 shows the proportion of total health resource use attributed to diabetes for each medical condition.

\section{Health care expenditures attributed to diabetes}

Health care expenditures attributed to diabetes reflect the additional expenditures the nation incurs because of diabetes. This equates to the total health care expenditures for people with diabetes minus the projected level of expenditures that would have occurred for those people in the absence of diabetes. Table 4 summarizes the national expenditure for the cost components analyzed, accounting for over $\$ 1.3$ trillion in projected

Table 4-Health care expenditures in the U.S. by diabetes status and type of service, 2012 (in millions of dollars)

\begin{tabular}{|c|c|c|c|c|c|c|}
\hline \multirow[b]{3}{*}{ Cost component } & \multicolumn{4}{|c|}{ Population with diabetes } & \multirow{3}{*}{$\begin{array}{l}\text { Population } \\
\text { without } \\
\text { diabetes }\end{array}$} & \multirow[b]{3}{*}{ Total* } \\
\hline & \multicolumn{2}{|c|}{$\begin{array}{l}\text { Attributed to } \\
\text { diabetes }\end{array}$} & \multicolumn{2}{|c|}{$\begin{array}{c}\text { Total incurred by } \\
\text { people with } \\
\text { diabetes }\end{array}$} & & \\
\hline & Dollars & $\begin{array}{l}\% \text { of U.S. } \\
\text { total }\end{array}$ & Dollars & $\begin{array}{l}\% \text { of U.S. } \\
\text { total }\end{array}$ & & \\
\hline \multicolumn{7}{|l|}{ Institutional care } \\
\hline Hospital inpatient & 75,872 & $16 \%$ & 123,726 & $26 \%$ & 351,618 & 475,344 \\
\hline Nursing/residential facility & 14,748 & $17 \%$ & 28,622 & $32 \%$ & 59,744 & 88,366 \\
\hline Hospice & 32 & $0.3 \%$ & 1,600 & $13 \%$ & 10,889 & 12,489 \\
\hline \multicolumn{7}{|l|}{ Outpatient care } \\
\hline Physician office & 15,221 & $8 \%$ & 31,443 & $17 \%$ & 155,226 & 186,669 \\
\hline Emergency department & 6,654 & $6 \%$ & 14,119 & $12 \%$ & 105,111 & 119,230 \\
\hline Ambulance services & 218 & $11 \%$ & 453 & $23 \%$ & 1,534 & 1,987 \\
\hline Hospital outpatient & 5,027 & $6 \%$ & 11,354 & $13 \%$ & 76,144 & 87,497 \\
\hline Home health & 4,466 & $9 \%$ & 11,269 & $23 \%$ & 37,264 & 48,533 \\
\hline Podiatry & 212 & $12 \%$ & 458 & $25 \%$ & 1,349 & 1,807 \\
\hline \multicolumn{7}{|c|}{ Outpatient medications and supplies } \\
\hline Insulin & 6,157 & $100 \%$ & 6,157 & $100 \%$ & 0 & 6,157 \\
\hline Diabetic supplies & 2,296 & $100 \%$ & 2,296 & $100 \%$ & 0 & 2,296 \\
\hline Other antidiabetic agents $\dagger$ & 12,137 & $100 \%$ & 12,137 & $100 \%$ & 0 & 12,137 \\
\hline Prescription medications & 31,716 & $12 \%$ & 59,067 & $22 \%$ & 208,662 & 267,729 \\
\hline $\begin{array}{l}\text { Other equipment and } \\
\text { supplies } \neq\end{array}$ & 1,063 & $4 \%$ & 3,593 & $15 \%$ & 20,076 & 23,669 \\
\hline Total & 175,819 & $13 \%$ & 306,293 & $23 \%$ & $1,027,617$ & $1,333,910$ \\
\hline
\end{tabular}

Data sources: NIS (2010), NNHS (2004), NAMCS (2008-2010), NHAMCS (2007-2009), MEPS (20062010), NHHCS (2007), and NHIS (2009-2011). †Includes oral medications and noninsulin injectable antidiabetic agents such as exenatide and pramlintide. ‡Includes, but not limited to eyewear, orthopedic items, hearing devices, prosthesis, bathroom aids, medical equipment, and disposable supplies. *Numbers do not necessarily sum to totals because of rounding. expenditure for 2012. Approximately $\$ 306$ billion of the total is incurred by people with diabetes, reflecting 23\% of the total health care dollars. Costs attributed to diabetes total $\$ 176$ billion, or $57 \%$ of the total medical costs incurred by people with diabetes. For the cost components analyzed, more than 1 in every 10 health care dollars is attributed to diabetes.

National health-related expenditures are projected to exceed $\$ 2.8$ trillion in 2012 , but slightly less than half of these expenditures are included in our analysis $(27,28)$. These cost estimates omit national expenditures (and any portion of such expenditures that might be attributable to diabetes) for administering government health and private insurance programs, investment in research and infrastructure, over-the-counter medications, disease management and wellness programs, and office visits to nonphysician providers other than podiatrists (e.g., dentists and optometrists). Expenditures for health resources such as care in residential mental retardation facilities are likewise excluded from the analysis.

More than $40 \%$ of all health care expenditures attributed to diabetes come from higher rates of hospital admission and longer average lengths of stay per admission, constituting the single largest contributor to the attributed medical cost of diabetes. Of the projected $\$ 475$ billion in national expenditures for hospital inpatient care (including both facility and professional services costs), approximately $\$ 124$ billion (or 26\%) is incurred by people who have diabetes, of which $\$ 76$ billion is directly attributed to their diabetes. Medications as a whole (prescription medications, insulin, and other antidiabetic agents) represent over onequarter $(28 \%)$ of all health expenditures attributed to diabetes. Of the projected $\$ 286$ billion in national cost for medications, $\$ 77$ billion (27\%) is incurred by people with diabetes, of which $\$ 50$ billion is attributed to their diabetes.

Approximately $59 \%$ of all health care expenditures attributed to diabetes are for health resources used by the population aged 65 years and older, much of which is borne by the Medicare program (Table 5). The population 45-64 years of age incurs $33 \%$ of diabetes-attributed costs, with the remaining $8 \%$ incurred by the population under 45 years of age. The annual attributed health care cost per person with diabetes (Table 6) increases with age, primarily as a result of increased use of 
Table 5-Health care expenditures attributed to diabetes in the U.S. by age-group and type of service, 2012 (in millions of dollars)

\begin{tabular}{|c|c|c|c|c|}
\hline \multirow[b]{2}{*}{ Cost component } & \multicolumn{3}{|c|}{ Age (years) } & \multirow[b]{2}{*}{$\begin{array}{c}\text { Total* } \\
(N=22.3 \mathrm{M}) \\
\end{array}$} \\
\hline & $\begin{array}{c}<45 \\
(n=3.3 \mathrm{M})\end{array}$ & $\begin{array}{c}45-64 \\
(n=10.2 \mathrm{M})\end{array}$ & $\begin{array}{c}\geq 65 \\
(n=8.8 \mathrm{M})\end{array}$ & \\
\hline \multicolumn{5}{|l|}{ Institutional care } \\
\hline Hospital inpatient & $4,924(6 \%)$ & $2,934(30 \%)$ & $48,015(63 \%)$ & 75,872 \\
\hline Nursing/residential facility & $211(1 \%)$ & $2,781(19 \%)$ & $11,757(80 \%)$ & 14,748 \\
\hline Hospice & $0(0 \%)$ & $3(9 \%)$ & $29(91 \%)$ & 32 \\
\hline \multicolumn{5}{|l|}{ Outpatient care } \\
\hline Physician office & $1,334(9 \%)$ & $4,882(32 \%)$ & $9,005(59 \%)$ & 15,221 \\
\hline Emergency department & $1,435(22 \%)$ & $2,363(36 \%)$ & $2,856(43 \%)$ & 6,654 \\
\hline Ambulance services & $20(9 \%)$ & $169(77 \%)$ & $29(13 \%)$ & 218 \\
\hline Hospital outpatient & $679(13 \%)$ & $1,943(39 \%)$ & $2,405(48 \%)$ & 5,027 \\
\hline Home health & $564(13 \%)$ & $1,806(40 \%)$ & $2,096(47 \%)$ & 4,466 \\
\hline Podiatry & $43(20 \%)$ & $61(29 \%)$ & $108(51 \%)$ & 212 \\
\hline \multicolumn{5}{|c|}{ Outpatient medications and supplies } \\
\hline Insulin & $1,102(18 \%)$ & $2,817(46 \%)$ & $2,239(36 \%)$ & 6,157 \\
\hline Diabetic supplies & $238(10 \%)$ & $1,003(44 \%)$ & $1,056(46 \%)$ & 2,296 \\
\hline Other antidiabetic agents $\dagger$ & $1,297(11 \%)$ & $5,767(48 \%)$ & $5,073(42 \%)$ & 12,137 \\
\hline Prescription medications & $2,443(8 \%)$ & $10,398(33 \%)$ & $18,875(60 \%)$ & 31,716 \\
\hline Other equipment and supplies $\$$ & $117(11 \%)$ & $309(29 \%)$ & $637(60 \%)$ & 1,063 \\
\hline Total & $14,406(8 \%)$ & $57,235(33 \%)$ & $104,178(59 \%)$ & 175,819 \\
\hline
\end{tabular}

Data sources: NIS (2010), NNHS (2004), NAMCS (2008-2010), NHAMCS (2007-2009), MEPS (20062010), NHHCS (2007), and NHIS (2009-2011). †Includes oral medications and noninsulin injectable antidiabetic agents. $¥$ Includes but not limited to eyewear, orthopedic items, hearing devices, prosthesis, bathroom aids, medical equipment, and disposable supplies. *Numbers do not necessarily sum to totals because of rounding.

hospital inpatient and nursing facility resources, physician office visits, and prescription medications. Dividing the total attributed health care expenditures by the number of people with diabetes, we estimate the average annual excess expenditures for the population aged under 45 years, 45-64 years, and 65 years and above, respectively, at $\$ 4,394, \$ 5,611$, and $\$ 11,825$. Total health care expenditures are attributed to diabetes by sex and race/ethnicity (Supplementary Table 6), insurance status (Supplementary Table 9 and 10), and state (Supplementary Table 11).

Table 7 summarizes diabetes-attributed health care expenditures for those cost components modeled by medical condition. Hospital inpatient is the largest component of attributed costs followed by physician office visit. Across different health care delivery settings, general medical conditions and cardiovascular disease categories are the two largest contributors of total health care expenditures attributed to diabetes in addition to diabetes itself. Together, the general medical conditions and cardiovascular disease categories are responsible for $78 \%$ of hospital inpatient costs attributed to diabetes,
$47 \%$ of the cost for physician office visits, $82 \%$ of the cost for emergency department visits, and $52 \%$ of the cost for hospital outpatient.

Figure 1 summarizes the proportion of medical expenditures attributed to diabetes for each chronic complication over the total U.S. health care expenditure combining expenditures for hospital inpatient, hospital outpatient, emergency department visits, physician office visits, and prescription medications. Over a quarter of expenditures, in five out of the eight conditions shown in the chart, are attributed to diabetes. In addition, 7 , 11 , and $21 \%$ of national medical expenditures treating general conditions, endocrine/ metabolic complications, and ophthalmic complications are attributable to diabetes.

The population with diabetes is older and sicker than the population without diabetes, and consequently annual medical expenditures are much higher (on average) than for people without diabetes (Table 8). After adjusting for age-sex differences in these two populations, people with diabetes have health care expenditures that are 2.3 times higher $(\$ 13,741$ vs. $\$ 5,853$ ) than expenditures would be expected for this same population in the absence of diabetes. This suggests that diabetes is responsible for $\$ 7,888$ in excess expenditures per year per person with diabetes. This 2.3 multiple is unchanged from the 2007 study.

\section{Indirect costs attributed to diabetes}

The total indirect cost of diabetes is estimated at $\$ 68.6$ billion (Table 9). The majority of this burden comes from unemployment due to permanent disability ( $\$ 21.6$ billion), presenteeism ( $\$ 20.8$ billion), and premature mortality ( $\$ 18.5$ billion). Workdays absent ( $\$ 5.0$ billion) and reduced productivity for those not in the workforce ( $\$ 2.7$ billion) represent a relatively small portion of the total burden.

Our logistic regression analysis with NHIS data suggests that diabetes is associated with a 2.4 percentage point increase in the likelihood of leaving the workforce for disability. This equates to approximately 541,000 working-age adults leaving the workforce prematurely and 130 million lost workdays in 2012. For the population that leaves the workforce early because of diabetes-associated disability, we estimate that their average daily earnings would have been $\$ 166$ per person (with the amount varying by demographic).

Presenteeism accounted for 30\% of the indirect cost of diabetes. The estimate of a $6.6 \%$ annual decline in productivity attributed to diabetes (in excess of the estimated decline in the absence of diabetes) equates to 113 million lost workdays per year. The average daily earnings are $\$ 185$ for the employed population with diabetes, which equates to $\$ 20.8$ billion in annual cost attributed to diabetes (after factoring out absenteeism to prevent double counting).

The estimated number of deaths in 2012 attributable to diabetes is 246,000 (Table 10). For 73,000 deaths (30\%), diabetes is listed as the primary cause. Of the 687,000 deaths where cardiovascular disease is listed as the primary cause, approximately 110,000 (16\%) are attributable to diabetes. Approximately 38,000 cases where cerebrovascular disease is listed as the primary cause of death are attributable to diabetes, and 25,000 cases where renal disease is listed as the primary cause of death are attributable to diabetes. The average cost per premature death declines with age (reflecting fewer remaining expected working years), and across all premature deaths averaged approximately $\$ 75,100$ per case. 
Table 6-Annual per capita health care expenditures attributed to diabetes in the U.S. by age-group and type of service, 2012 (in actual dollars)

\begin{tabular}{|c|c|c|c|c|}
\hline \multirow[b]{2}{*}{ Cost component } & \multicolumn{3}{|c|}{ Age (years) } & \multirow[b]{2}{*}{$\begin{array}{c}\text { All ages } \\
(\mathrm{N}=22.3 \mathrm{M})\end{array}$} \\
\hline & $\begin{array}{c}<45 \\
(n=3.3 \mathrm{M})\end{array}$ & $\begin{array}{c}45-64 \\
(n=10.2 \mathrm{M})\end{array}$ & $\begin{array}{c}\geq 65 \\
(n=8.8 \mathrm{M})\end{array}$ & \\
\hline \multicolumn{5}{|l|}{ Institutional care } \\
\hline Hospital inpatient & 1,502 & 2,248 & 5,450 & 3,404 \\
\hline Nursing/residential facility & 64 & 273 & 1,334 & 662 \\
\hline Hospice & 0.01 & 0.29 & 3 & 1 \\
\hline \multicolumn{5}{|l|}{ Outpatient care } \\
\hline Physician office & 407 & 479 & 1,022 & 683 \\
\hline Emergency department & 438 & 232 & 324 & 299 \\
\hline Ambulance services & 6 & 17 & 3 & 10 \\
\hline Hospital outpatient & 207 & 191 & 273 & 226 \\
\hline Home health & 172 & 177 & 238 & 200 \\
\hline Podiatry & 13 & 6 & 12 & 10 \\
\hline \multicolumn{5}{|l|}{ Outpatient medications and supplies } \\
\hline Insulin & 336 & 276 & 254 & 276 \\
\hline Diabetic supplies & 73 & 98 & 120 & 103 \\
\hline Other antidiabetic agents $\dagger$ & 396 & 565 & 576 & 544 \\
\hline Prescription medications & 745 & 1,019 & 2,142 & 1,423 \\
\hline Other equipment and supplies $\ddagger$ & 36 & 30 & 72 & 48 \\
\hline Total $*$ & 4,394 & 5,611 & 11,825 & 7,888 \\
\hline
\end{tabular}

Data sources: NIS (2010), NNHS (2004), NAMCS (2008-2010), NHAMCS (2007-2009), MEPS (20062010), NHHCS (2007), NHIS (2009-2011), and the U.S. Census Bureau (2012). †Includes oral medications and noninsulin injectable antidiabetic agents. $\$$ Includes but not limited to eyewear, orthopedic items, hearing devices, prosthesis, bathroom aids, medical equipment, and disposable supplies. *Numbers do not necessarily sum to totals because of rounding.

Figure 2 summarizes estimates of PVFP if a person dies at that age. PVFP is the value in 2012 of expected future lifetime earnings if the person had lived to the average age as the cohort born in the same year. The differences in PVFP by demographic reflect the differences in average earnings, the propensity to be in the workforce, and the number of years expected to remain in the workforce.

The cost of missed workdays due to absenteeism is estimated at $\$ 5.0$ billion, representing 25 million days. If people not in the workforce have similar rates of days where they are unable to work due to poor health as their employed peers, this would equate to 20 million excess sick days with the estimated productivity loss valued at $\$ 2.7$ billion. We do not count productivity loss for the population under age 18 years. While children constitute a small proportion of the population with diabetes, omitting productivity loss associated with diabetes among children will tend to bias low the cost estimates. For example, the economic cost associated with parents who take time off from work to take their children to the doctor for diabetes-related visits is omitted from these cost estimates.
The average annual productivity loss per person aged 18 years or older with diabetes is $\$ 3,100$. Table 11 shows that per capita estimates range from a high of $\$ 6,844$ for men aged $45-54$ years to a low of $\$ 647$ for women aged 70 years and older-reflecting differences by demographic in propensity to be in the workforce, average earnings, and mortality risk. Supplementary Table 7 shows the annual productivity loss per person with diabetes by cause and race/ethnicity.

CONCLUSIONS - This study found that there were more than 22.3 million people (about $7 \%$ of the U.S. population) with diagnosed diabetes in the U.S. in 2012. This is substantially higher than the 2007 estimate of 17.5 million people, reflecting changing demographics, increase in the prevalence of risk factors including obesity, decreasing mortality, and improvements in the detection of diabetes (29-32). Diabetes costs the nation a total of $\$ 245$ billion, which includes $\$ 176$ billion in direct medical cost and $\$ 69$ billion in lost productivity. While the majority (59\%) of direct medical cost is for the population aged 65 years and over, about $88 \%$ of indirect cost is borne by the population under 65 years of age. We also found that after adjusting for age and sex, annual per capita health care expenditure is 2.3 times higher for people with diabetes than for those without diabetes. Diabetes is especially costly when it is associated with complications. While we were unable to calculate diabetes-attributed cost by complication groups for every cost component across the major health care delivery settings (hospital inpatient and outpatient, physician office, and emergency department), from 25\% (emergency department) to $45 \%$ (hospital inpatient) of the diabetes-attributed medical expenditures were spent treating complications of diabetes. Other studies found that people with uncontrolled diabetes or with diabetes complications incur diabetes costs two to eight times more than people with controlled or nonadvanced diabetes $(33,34)$.

For comparison, the $\$ 174$ billion estimate of the total burden for 2007 published previously is equivalent to $\$ 202$ billion when inflated to 2012 dollars using the average general inflation rate of $3 \%$. The increase of $\$ 43$ billion from the 2007 estimate in 2012 dollars to the new estimate of $\$ 245$ billion reflects 1) a $27 \%$ growth in diabetes prevalence, 2) changing demographics of people with diabetes, 3) growth in the utilization of certain types of health care services for treating diabetes and its comorbidities such as increased use of prescription medications and advanced treatment for cardiovascular disease, 4) rising prices for medical goods and services above the general rate of inflation, and 5) refinements to the data and methods used to calculate the cost of diabetes.

We found that the proportions of total national health services use attributed to diabetes and incurred by people with diabetes both increased from the estimates in the 2007 study, including utilization of nursing/residential facility days, physician office visits, emergency department visits, hospital outpatient visits, and prescription medications. The number of hospital inpatient days incurred by people with diabetes and those that are attributable to their diabetes have both increased from the 2007 level by about 6 and $9 \%$, respectively, although the national utilization of hospital inpatient care has decreased by about 10\% from 186 million days in 2007 to 168 million days in 2012 based on the analysis of NIS data. 
Additionally, even when using MEPS data that have been shown to underestimate costs when compared with claims data, especially for the privately insured (35), we found that the price of medical services per event (visit or day) has increased by $5-17 \%$ over the rate of general inflation from the 2007 level for hospital inpatient, hospital outpatient, emergency department, insulin, and other prescription medications. Due to the increase in diabetes prevalence, health resource utilization, and average per event cost of services, the $\$ 176$ billion direct medical cost attributed to diabetes in 2012 is 30\% higher than the general inflation-adjusted 2007 direct medical cost of $\$ 135$ billion.

The indirect cost estimate of $\$ 69$ billion for 2012 includes increased absenteeism ( $\$ 5$ billion) and reduced productivity while at work ( $\$ 20.8$ billion) for the employed population, reduced productivity for those not in the labor force ( $\$ 2.7$ billion), unemployment as a result of disease-related disability ( $\$ 21.6$ billion), and lost productive capacity due to early mortality ( $\$ 18.5$ billion). The $\$ 69$ billion is only 3\% higher than the inflation-adjusted 2007 estimate of $\$ 67$ billion, despite the $27 \%$ growth in diabetes prevalence. Factors depressing the 2012 estimate include the decline in the number of people participating in the workforce in 2012 and the lower diabetes-attributed mortality estimates for 2012. Including race/ethnicity as a study dimension also depressed the national indirect burden estimate relative to 2007 , as Hispanics and non-Hispanic blacks have higher diabetes prevalence rates but lower labor force participation rates and lower average earnings. Since the 2007 study, the economic downturn has decreased overall rates of employment across all demographic groups regardless of diabetes status. A declining proportion of the adult population in the workforce depresses the estimates of absenteeism and presenteeism, while increasing the estimates of diabetesrelated productivity losses for the population not in the workforce.

Our estimate of $\$ 245$ billion only represents the economic cost of diagnosed diabetes. An earlier study found that 6.3 million U.S. adults have undiagnosed diabetes with an associated cost of $\$ 18$ billion in 2007 (36). Furthermore, nearly 57 million adults in that study were estimated to have prediabetes, a precursor to diabetes, costing an additional $\$ 25$ billion in higher medical spending $(37,38)$. On the surface it appears that the financial burden of diabetes falls primarily on insurers who pay a substantial portion of medical costs, employers who experience productivity loss, and the people with diabetes and their families who incur higher out-of-pocket medical costs and reduced earnings potential or employment opportunities. Ultimately, though, the burden is passed along to all of society in the form of higher insurance premiums and taxes,

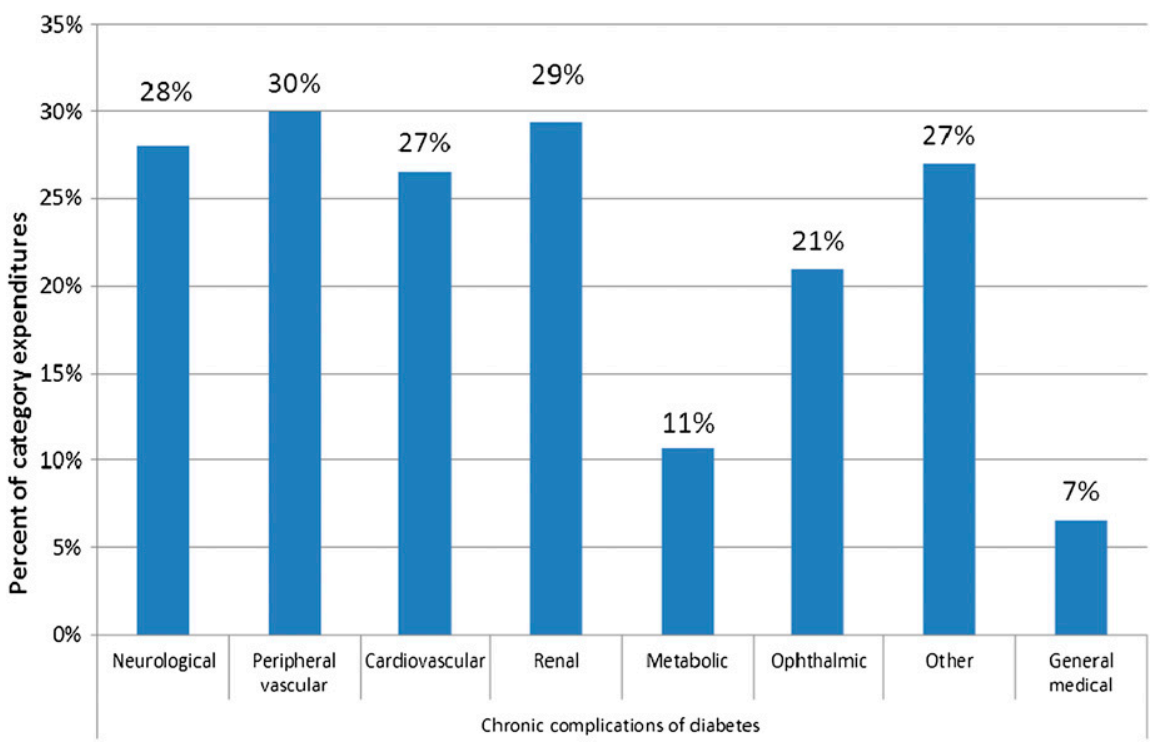

Figure 1-Percent of medical condition-specific expenditures associated with diabetes. Data sources: NIS (2010), NAMCS (2008-2010), NHAMCS (2007-2009), and MEPS (2006-2010 or 2008-2010). Note: See Supplementary Table 2 for diagnosis codes for each category of medical condition. 


\begin{tabular}{|c|c|c|c|c|c|c|}
\hline \multirow[b]{2}{*}{ Cost component } & \multirow[b]{2}{*}{ With diabetes $(\$)$} & \multicolumn{2}{|c|}{ Unadjusted } & \multicolumn{3}{|c|}{ Adjusted for age and sex } \\
\hline & & $\begin{array}{c}\text { Without } \\
\text { diabetes }(\$)\end{array}$ & $\begin{array}{c}\text { Ratio with to } \\
\text { without diabetes }\end{array}$ & $\begin{array}{c}\text { Without } \\
\text { diabetes }(\$)\end{array}$ & $\begin{array}{c}\text { Ratio with to } \\
\text { without diabetes }\end{array}$ & $\begin{array}{c}\text { Attributed to } \\
\text { diabetes }(\$)\end{array}$ \\
\hline \multicolumn{7}{|l|}{ Institutional care } \\
\hline Hospital inpatient & 5,551 & 1,196 & 4.6 & 2,147 & 2.6 & 3,404 \\
\hline Nursing/residential facility & 1,284 & 203 & 6.3 & 622 & 2.1 & 662 \\
\hline Hospice & N/A & N/A & N/A & N/A & N/A & N/A \\
\hline \multicolumn{7}{|l|}{ Outpatient care } \\
\hline Physician office & 1,411 & 528 & 2.7 & 728 & 1.9 & 683 \\
\hline Emergency & 633 & 357 & 1.8 & 335 & 1.9 & 299 \\
\hline Ambulance services & 20 & 5 & 3.9 & 11 & 1.9 & 10 \\
\hline $\begin{array}{l}\text { Hospital outpatient and freestanding } \\
\text { ambulatory surgical center }\end{array}$ & 509 & 259 & 2.0 & 284 & 1.8 & 226 \\
\hline Home health & 506 & 127 & 4.0 & 305 & 1.7 & 200 \\
\hline Podiatry & 21 & 5 & 4.5 & 11 & 1.9 & 10 \\
\hline \multicolumn{7}{|l|}{ Outpatient medications and supplies } \\
\hline Insulin & 276 & NA & NA & NA & NA & 276 \\
\hline Diabetic supplies & 103 & NA & NA & NA & NA & 103 \\
\hline Other antidiabetic agents $\dagger$ & 544 & NA & NA & NA & NA & 544 \\
\hline Prescription medications & 2,650 & 710 & 3.7 & 1,227 & 2.2 & 1,423 \\
\hline Other equipment and supplies $\$$ & 161 & 68 & 2.4 & 113 & 1.4 & 48 \\
\hline Total & 13,741 & 3,495 & 3.9 & 5,853 & 2.3 & 7,888 \\
\hline
\end{tabular}

Data sources: NIS (2010), NNHS (2004), NAMCS (2008-2010), NHAMCS (2007-2009), MEPS (2006-2010), NHHCS (2007), NHIS (2009-2011), and the U.S. Census Bureau (2012). N/A, not available; NA, not applicable. †Includes antidiabetic agents such as exenatide and pramlintide. $\ddagger$ Includes but not limited to eyewear, orthopedic items, hearing devices, prosthesis, bathroom aids, medical equipment, and disposable supplies.

reduced earnings, and reduced standard of living.

The cost estimates presented might be conservative for several reasons:

- Due to data limitations, we omitted from this analysis the potential increase in the use of over-the-counter medications and optometry and dental services. Diabetes increases the risk of periodontal disease, so one would expect dental costs to be higher for people with diabetes. We explored the MEPS data for the feasibility of capturing optometry and dental costs, but the small sample sizes prevented meaningful analyses. Also omitted from the cost estimates are expenditures for the prevention programs targeted to people with diabetes (e.g., disease management programs), research activities (e.g., to develop new drugs), and administration costs (e.g., to administer the Medicare and Medicaid programs, to process insurance claims). Administration costs for government health programs and private insurers are $\sim \$ 150$ billion per year. Public and private expenditures for medical research and health infrastructure total over $\$ 130$ billion per year (39). If a portion of these costs were attributed to diabetes, the national cost of diabetes would be billions of dollars higher than our estimate suggests.

- Also omitted from the cost estimates are the intangible costs of diabetes such

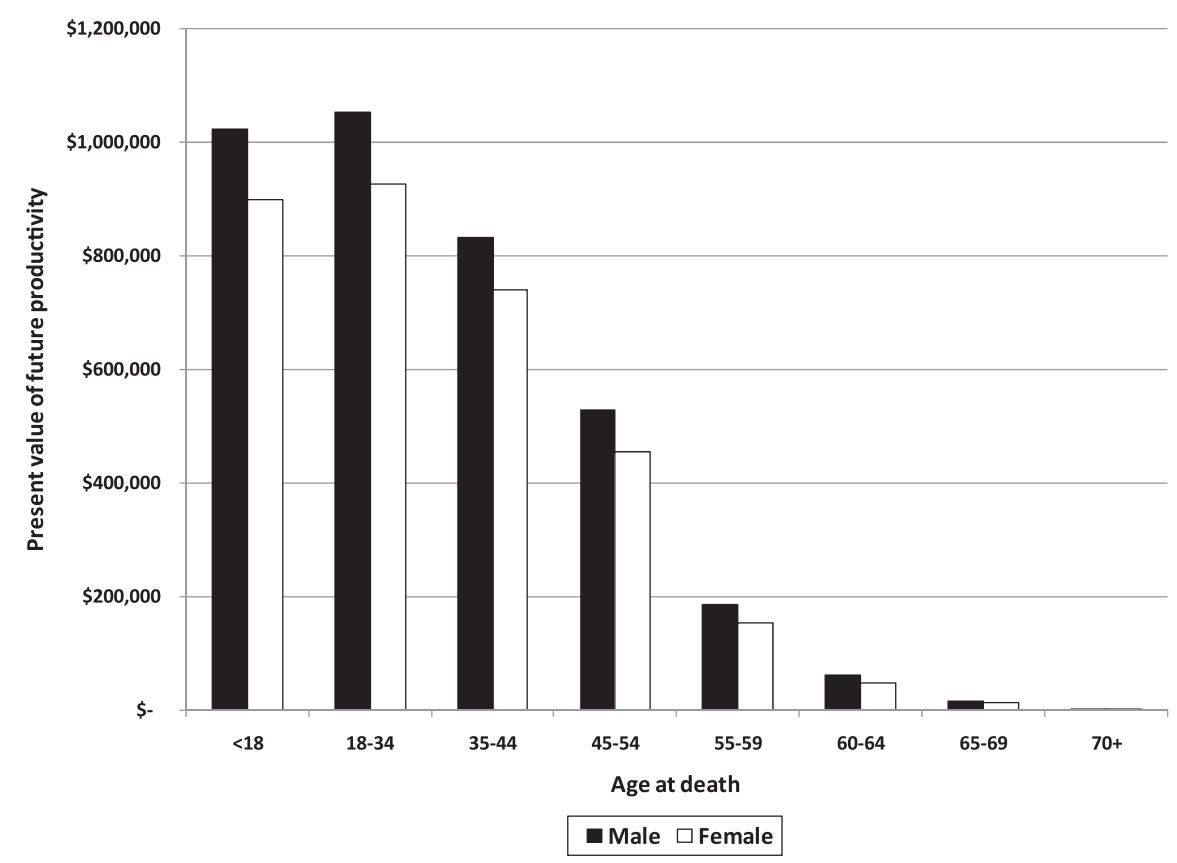

Figure 2-Net present value of future lost earnings from premature death. Data sources: analysis of the NHIS (2009-2011), CPS (2011), and CDC mortality data. 
Table 9-Indirect burden of diabetes in the U.S., 2012 (in billions of dollars)

\begin{tabular}{|c|c|c|c|}
\hline Cost component & Productivity loss & $\begin{array}{c}\text { Total cost attributable } \\
\text { to diabetes }(\$)\end{array}$ & $\begin{array}{l}\text { Proportion of } \\
\text { indirect costs* }\end{array}$ \\
\hline Workdays absent & 25 million days & 5.0 & $7 \%$ \\
\hline Reduced performance at work & 113 million days & 20.8 & $30 \%$ \\
\hline $\begin{array}{l}\text { Reduced productivity days for } \\
\text { those not in labor force }\end{array}$ & 20 million days & 2.7 & $4 \%$ \\
\hline $\begin{array}{l}\text { Reduced labor force participation } \\
\text { due to disability }\end{array}$ & 130 million days & 21.6 & $31 \%$ \\
\hline Mortality & 246,000 deaths & 18.5 & $27 \%$ \\
\hline Total & & 68.6 & $100 \%$ \\
\hline
\end{tabular}

Data sources: analysis of the NHIS (2009-2011), CPS (2011), CDC mortality data, and the U.S. Census Bureau population estimates for 2010 and 2012. *Numbers do not necessarily sum to totals because of rounding. renal complications, or lower-extremity amputations often require their homes and/or motor vehicles to be modified to accommodate their daily activity needs. Diabetes is the leading cause of new cases of blindness among adults aged 20-74 years (23), and the CDC estimates that roughly 65,700 lower-limb amputations are performed each year on people with diabetes (23). The nonmedical cost associated with these disabilities could further increase the total burden of diabetes.

- The lost productivity estimates are for those individuals with diagnosed diabetes and exclude lost productivity associated with the care for family members with diabetes. For example, the productivity loss associated with adults who take time off from work to care for a child or an elderly parent with diabetes is not included in the cost estimates. The value of informal caregiving is excluded from our cost estimate. Time and costs associated with traveling to doctor visits and other medical emergencies are omitted (except to the extent that such costs are partially captured under ambulance costs and the absenteeism estimate for those in the workforce).

- Our estimate of lost productivity attributed to chronic disability from diabetes is also likely to be conservative due to three factors: 1) using SSI payments to identify cases of disability likely underestimates disability cases because the criteria for SSI eligibility include requirements for documentation of disability from a health professional and apply income limits; 2) these estimates omit the value of productivity loss that results in reduced earnings potential but does not prevent working; and 3) productivity loss associated with early retirement is not included, and a longitudinal study using the Health and Retirement Survey found that people with diabetes tend to retire $\sim 1.2$ years earlier than their peers without diabetes (40).

One challenge for this study was to control for the correlation between diabetes and the use of health resources for
Table 10-Mortality costs attributed to diabetes, 2012

\begin{tabular}{lcccc} 
& & \multicolumn{3}{c}{ Deaths attributed to diabetes } \\
\cline { 3 - 5 } $\begin{array}{l}\text { Total U.S. } \\
\text { deaths }\end{array}$ & $\begin{array}{c}\text { Deaths } \\
\text { Primary cause of death }\end{array}$ & $\begin{array}{c}\text { \% of U.S. } \\
\text { deaths in } \\
\text { (thousands) }\end{array}$ & $\begin{array}{c}\text { Value of lost } \\
\text { productivity } \\
\text { (thousands) }\end{array}$ & $\begin{array}{c}\text { category } \\
\text { (millions of dollars) }\end{array}$ \\
\hline Diabetes & 73 & 73 & $100.0 \%$ & 7,147 \\
Renal disease & 46 & 25 & $55.0 \%$ & 2,004 \\
Cerebrovascular disease & 136 & 38 & $28.0 \%$ & 1,484 \\
Cardiovascular disease & 687 & 110 & $16.0 \%$ & 7,827 \\
Total & N/A & 246 & N/A & 18,462
\end{tabular}

* Data source: CDC National Vital Statistics Reports for total deaths in 2009 by primary cause of death, scaled to 2012 using the annual diabetic population growth rate from 2009 to 2012 for each age, sex, and race/ ethnicity group (42). reasons not directly attributed to diabetes. Health behavior that affects both the presence of diabetes and the presence of other comorbidities, unless controlled for, could result in an overestimation of the link between diabetes and the use of health resources. Controlling for age, sex, and race/ethnicity helps to control for this correlation. In addition, for the top 10 cost drivers, we conducted additional analysis controlling for other important explanatory variables using the MEPS data. Based on the results, we reduced the etiological fractions for several diabetes complications and for the general medical conditions group depending on the setting of care. This potential limitation also applies to the estimates of indirect costs attributed to diabetes, especially the estimated productivity loss due to presenteeism.

Other study limitations discussed previously include small sample size for some data sources used, the use of a data source (dNHI) that overrepresents the commercially insured population for the population younger than age 65 years, and the need to use different approaches to model different cost components because of data limitations. Another limitation common to claims-based analysis is the possibility of inaccurate diagnosis codes. Claims data tend to be less accurate than medical records in identifying patients with specific conditions due to reasons such as rule-out diagnosis, coding error, etc. The direction of such bias on our risk ratio calculations is unknown, although it is anticipated to be small as there is no reason to believe that the coding of comorbidities would be significantly different for people with and without diabetes.

Using a methodology that is largely consistent with our previous cost of diabetes study in 2007 with updated national survey and claims data from previous data sources, we estimated the total burden of diabetes in 2012. The estimates presented here show that diabetes places an enormous burden on society-both in the economic terms presented here and in reduced quality of life. The overall cost of diabetes estimates are consistent with earlier estimates after adjusting for the increasing prevalence of diabetes and price increases (though estimates for some cost components and medical conditions differ from the earlier study).

A recent study estimates that prevalence of diagnosed diabetes is likely to at least double between 2010 and 2050, and 
Table 11-Annual productivity loss per person with diabetes in the U.S. by age, sex, and cause, 2012 (in actual dollars)

\begin{tabular}{|c|c|c|c|c|c|c|c|}
\hline Sex & Age & Absenteeism & Presenteeism & $\begin{array}{l}\text { Reduced productivity for } \\
\text { those not in labor force }\end{array}$ & $\begin{array}{l}\text { Unemployment } \\
\text { from disability }\end{array}$ & $\begin{array}{c}\text { Premature } \\
\text { mortality }\end{array}$ & $\begin{array}{c}\text { Total annual } \\
\text { burden }\end{array}$ \\
\hline \multirow[t]{7}{*}{ Male } & $18-34$ & 170 & 1,147 & 61 & 769 & 2,408 & 4,556 \\
\hline & $35-44$ & 403 & 2,187 & 117 & 1,341 & 2,442 & 6,490 \\
\hline & $45-54$ & 811 & 1,691 & 336 & 1,416 & 2,591 & 6,844 \\
\hline & $55-59$ & 419 & 1,816 & 221 & 1,577 & 1,116 & 5,149 \\
\hline & $60-64$ & 211 & 1,530 & 188 & 1,413 & 463 & 3,805 \\
\hline & $65-69$ & 89 & 878 & - & 417 & 209 & 1,593 \\
\hline & $70+$ & - & 305 & - & 503 & 68 & 876 \\
\hline Total & & 298 & 1,246 & 135 & 1,034 & 1,100 & 3,813 \\
\hline \multirow[t]{7}{*}{ Female } & $18-34$ & 114 & 769 & 66 & 798 & 1,100 & 2,847 \\
\hline & $35-44$ & 241 & 1,310 & 113 & 1,228 & 1,409 & 4,301 \\
\hline & $45-54$ & 436 & 908 & 297 & 1,241 & 1,340 & 4,222 \\
\hline & $55-59$ & 224 & 970 & 196 & 1,453 & 559 & 3,401 \\
\hline & $60-64$ & 93 & 679 & 142 & 1,224 & 256 & 2,394 \\
\hline & $65-69$ & 36 & 354 & - & 343 & 116 & 849 \\
\hline & $70+$ & - & 132 & - & 469 & 46 & 647 \\
\hline Total & & 149 & 614 & 111 & 901 & 548 & 2,322 \\
\hline
\end{tabular}

Data sources: analysis of the NHIS (2009-2011), CPS (2011), and CDC mortality data. Note: Age <18 years is not included as no indirect costs are calculated for persons under the age of 18 . For the age 70 years and older population, the rate of labor force participation is low so indirect costs are relatively low for this population despite high prevalence of diabetes. The NHIS sample size of employed people over age 70 years is small, and regression analysis with the NHIS found that diabetes is not associated with increased workdays absent for illness among the employed population aged 70 years and older. We conservatively assume that for the population aged 65 years and older and not in the workforce there is no loss in societal productivity (e.g., from volunteer work) associated with diabetes.

the prevalence of total diabetes (diagnosed and undiagnosed) may increase from the 2010 level of about one in nine adults to between one in five and one in three adults in $2050(3,41)$.

This study highlights the large economic burden of diabetes and its complications on the individual and the health care system. Cost estimates from 2002, 2007, and now 2012 show that the burden is increasing - even after controlling for population growth and inflation. Cost comparisons by age-group show that the burden of diabetes increases with age. These trends underscore the importance of prevention and the efforts to mitigate the complications of diabetes.

Acknowledgments-No potential conflicts of interest relevant to this article were reported.

\section{References}

1. American Diabetes Association. Economic costs of diabetes in the U.S. in 2002. Diabetes Care 2003;26:917-932

2. American Diabetes Association. Economic costs of diabetes in the U.S. in 2007. Diabetes Care 2008;31:596-615

3. Boyle JP, Thompson TJ, Gregg EW, Barker LE, Williamson DF. Projection of the year 2050 burden of diabetes in the US adult population: dynamic modeling of incidence, mortality, and prediabetes prevalence. Popul Health Metr 2010;8:29
4. U.S. Census Bureau. Population Projections: 2008 National Population Projections [Internet], 2008. Available from http:// www.census.gov/population/projections/ data/national/2008.html. Accessed 16 January 2013

5. U.S. Bureau of Labor Statistics. Consumer Price Index: CPI Databases [Internet]. Available from http://www.bls.gov/cpi/ data.htm. Accessed 16 January 2013

6. Okura Y, Urban LH, Mahoney DW, Jacobsen SJ, Rodeheffer RJ. Agreement between self-report questionnaires and medical record data was substantial for diabetes, hypertension, myocardial infarction and stroke but not for heart failure. J Clin Epidemiol 2004;57:10961103

7. Dybicz SB, Thompson S, Molotsky S, Stuart B. Prevalence of diabetes and the burden of comorbid conditions among elderly nursing home residents. Am J Geriatr Pharmacother 2011;9:212-223

8. American Diabetes Association. Diabetes management in correctional institutions (Position Statement). Diabetes Care 2011; 34(Suppl. 1):S75-S81

9. Paris RM, Bedno SA, Krauss MR, Keep LW, Rubertone MV. Weighing in on type 2 diabetes in the military: characteristics of U.S. military personnel at entry who develop type 2 diabetes. Diabetes Care 2001; 24:1894-1898

10. U.S. Centers for Disease Control and Prevention. CDC's State Surveillance Data. Available from http://www.cdc.gov/ nceh/lead/data/state.htm. Accessed 16 January 2013
11. Osborn DP, Holt, R. Diabetes and mental health. In Diabetes: Chronic Complications. 3rd ed. Shaw KM, Cummings MH, Eds. Hoboken, NJ, John Wiley \&Sons, Inc., 2012, p. 214-239

12. Vigneri P, Frasca F, Sciacca L, Pandini G, Vigneri R. Diabetes and cancer. Endocr Relat Cancer 2009;16:1103-1123

13. Egede LE, Zheng D, Simpson K. Comorbid depression is associated with increased health care use and expenditures in individuals with diabetes. Diabetes Care 2002;25:464-470

14. Benichou J. A review of adjusted estimators of attributable risk. Stat Methods Med Res 2001;10:195-216

15. Genworth Financial. Genworth 2012 Cost of Care Survey [Internet], 2012. Genworth Financial, Inc., Richmond, VA. Available from wwwl.genworth.com/ content/etc/medialib/genworth_v2/pdf/ ltc_cost_of_care.Par.40001.File.dat/2012\% 20Cost $\% 20$ of\%20Care\%20Survey\%20Full \%20Report.pdf. Accessed 16 January 16 2013

16. Cawley J, Rizzo JA, Haas K. The association of diabetes with job absenteeism costs among obese and morbidly obese workers. J Occup Environ Med 2008;50:527-534

17. Fu AZ, Qiu Y, Radican L, Wells BJ. Health care and productivity costs associated with diabetic patients with macrovascular comorbid conditions. Diabetes Care 2009;32:2187-2192

18. Lee LJ, Yu AP, Cahill KE, et al. Direct and indirect costs among employees with diabetic retinopathy in the United States. Curr Med Res Opin 2008;24:1549-1559 
19. DiBonaventura M, Link C, Pollack MF, Wagner J-S, Williams SA. The relationship between patient-reported tolerability issues with oral antidiabetic agents and work productivity among patients having type 2 diabetes. J Occup Environ Med 2011;53:204-210

20. Lamb CE, Ratner PH, Johnson CE, et al. Economic impact of workplace productivity losses due to allergic rhinitis compared with select medical conditions in the United States from an employer perspective. Curr Med Res Opin 2006;22:1203-1210

21. Loeppke R, Taitel M, Haufle V, Parry T, Kessler RC, Jinnett K. Health and productivity as a business strategy: a multiemployer study. J Occup Environ Med 2009;51:411-428

22. Rodbard HW, Fox KM, Grandy S; Shield Study Group. Impact of obesity on work productivity and role disability in individuals with and at risk for diabetes mellitus. Am J Health Promot 2009;23: 353-360

23. U.S. Centers for Disease Control and Prevention. Diabetes Public Health Resource: 2011 National Diabetes Fact Sheet [Internet], 2011. Available from http:// www.cdc.gov/diabetes/pubs/estimates11. htm. Accessed 16 January 2013

24. Wolf AM, Siadaty MS, Crowther JQ, et al. Impact of lifestyle intervention on lost productivity and disability: improving control with activity and nutrition. J Occup Environ Med 2009;51:139-145

25. Carnethon MR, Biggs ML, Barzilay J, et al. Diabetes and coronary heart disease as risk factors for mortality in older adults. Am J Med 2010;123:556.el-e9

26. U.S. Centers for Disease Control and Prevention. Diabetes Data \& Trends:
Number (in Millions) of Civilian, Noninstitutionalized Persons with Diagnosed Diabetes, United States, 1980-2010 [Internet], 2011. Available from http://www. cdc.gov/diabetes/statistics/prev/national/ figpersons.htm. Accessed 17 January 2013

27. Poisal JA, Truffer C, Smith S, et al. Health spending projections through 2016: modest changes obscure Part D's impact. Health Aff (Millwood) 2007;26:w242-w253

28. Smith C, Cowan C, Heffler S, Catlin A. National health spending in 2004: recent slowdown led by prescription drug spending. Health Aff (Millwood) 2006;25:186196

29. U.S. Centers for Disease Control and Prevention. Overweight and Obesity: Adult Obesity Facts [Internet], 2012. Available from http://www.cdc.gov/obesity/data/ adult.html. Accessed 16 January 2013

30. Hoyert DL. 75 Years of Mortality in the United States, 1935-2010. NCHS data brief, no. 88. Hyattsville, MD, National Center for Health Statistics, 2012

31. U.S. Preventive Services Task Force. Screening for Type 2 Diabetes Mellitus in Adults [Internet], 2008. Available from http://www.uspreventiveservicestaskforce. org/uspstf/uspsdiab.htm. Accessed 16 January 2013

32. Mokdad AH, Ford ES, Bowman BA, et al. Prevalence of obesity, diabetes, and obesityrelated health risk factors, 2001. JAMA 2003;289:76-79

33. Kim S. Burden of hospitalizations primarily due to uncontrolled diabetes: implications of inadequate primary health care in the United States. Diabetes Care 2007;30:1281-1282

34. Brown JB, Pedula KL, Bakst AW. The progressive cost of complications in type 2 diabetes mellitus. Arch Intern Med 1999; 159:1873-1880

35. Aizcorbe A, Liebman E, Pack S, Cutler DM, Chernew ME, Rosen AB. Measuring health care costs of individuals with employersponsored health insurance in the U.S.: a comparison of survey and claims data. Journal of the International Association for Official Statistics 2012;28:43-51

36. Zhang Y, Dall TM, Mann SE, et al. The economic costs of undiagnosed diabetes. Popul Health Manag 2009;12:95-101

37. Zhang Y, Dall TM, Chen Y, et al. Medical cost associated with prediabetes. Popul Health Manag 2009;12:157-163

38. Dall TM, Zhang Y, Chen YJ, Quick WW, Yang WG, Fogli J. The economic burden of diabetes. Health Aff (Millwood) 2010; 29:297-303

39. Centers for Medicare \& Medicaid Services. National Health Expenditure Projections 2010-2020: Forecast Summary. Available from https://www.cms.gov/ResearchStatistics-Data-and-Systems/StatisticsTrends-and-Reports/NationalHealthExpend Data/downloads/proj2010.pdf. Accessed 17 January 2013

40. Vijan S, Hayward RA, Langa KM. The impact of diabetes on workforce participation: results from a national household sample. Health Serv Res 2004;39(6 Pt 1): 1653-1669

41. Narayan KM, Boyle JP, Geiss LS, Saaddine JB, Thompson TJ. Impact of recent increase in incidence on future diabetes burden: U.S., 2005-2050. Diabetes Care 2006;29: 2114-2116

42. Hoyert DL, Xu JQ. Deaths: Preliminary Data for 2011. National Vital Statistics Reports, vol. 61, no. 6. Hyattsville, MD, National Center for Health Statistics, 2012 